\title{
In Memory of Professor Susanne Rässler
}

\author{
Jörg Drechsler, Hans Kiesl, Florian Meinfelder, Trivellore E. Raghunathan, \\ Donald B. Rubin, Nathaniel Schenker, and Elizabeth R. Zell
}

On the 29th of August 2018, Susanne Rässler, long-term associate editor of the Journal of Official Statistics, died far too early at the age of 55. All who knew her agree that she was a very special person. As Danny Pfeffermann said: "You could not just be a colleague. You had to be a friend."

Susanne received her $\mathrm{PhD}$ in Statistics from the Friedrich-Alexander Universität Erlangen-Nürnberg (FAU) in Germany in 1995 with a thesis comparing several estimators in unequal probability sampling. Following an offer to join the Department of Statistics and Econometrics at the FAU as a faculty member, she started her research in the field of statistical matching of multiple data sources, which culminated in her seminal book Statistical matching: A frequentist theory, practical applications, and alternative Bayesian approaches published in 2002. Two years later she temporarily left academia to accept a split appointment at the headquarters of the German Federal Employment Agency (BA) and the Institute for Employment Research (IAB), the research branch of the BA.

Despite working at the BA and the IAB for only three years, Susanne had a lasting impact at both institutions. At the IAB she established the Department for Statistical Methods and initiated numerous research projects on missing data, sampling designs, multiple imputation, and statistical disclosure control. Under her guidance, the IAB got involved in cutting edge research on methodological questions related to official statistics. As early as 2005, the institute experimented with split questionnaire designs to reduce the response burden of survey participants and to increase the quality of the gathered information. The institute was also the first statistical agency outside the United States to release multiply-imputed synthetic datasets to facilitate access to its highly sensitive establishment survey data for external researchers. Arguably, the most influential project initiated during her time at the IAB was a joint research project between the institute, the BA and Harvard University called TrEffeR (Treatment Effects and Prediction). The joint research enabled the BA for the first time to obtain detailed evaluations of its training measures based on the potential outcomes approach for causal inference (Rubin's Causal Model). The sophisticated procedures for matching treated and controls using the rich administrative databases available at the BA are still used today to evaluate all labor market programs offered by the Federal Employment Agency as well as for evaluating the relative effectiveness of the different providers of these programs.

In 2007 Susanne was appointed to the Chair of Statistics and Econometrics at the University of Bamberg, a position she held until her death. Because of her charming and warm personality, at Bamberg she was equally popular among students and academic colleagues, and her numerous committee positions within the faculty are testimony of her tireless commitment and dedication. In 2010 she initiated a new master's program in 
Survey Statistics, which over the years evolved into one of the largest Statistics programs in Germany with currently over 100 enrolled students. In the same year, the University of Bamberg started the National Educational Panel Study (NEPS), a large scale multi-cohort longitudinal study with more than 60,000 participants. Susanne was the obvious choice for the head of the Statistical Methods Department of the NEPS and later became the scientific director of the same department, when the NEPS was integrated into the newly founded Leibniz Institute for Empirical Educational Trajectories (LIfBi).

Stimulating the exchange of ideas and fostering statistical literacy was always important for Susanne. She tirelessly worked to bridge communication gaps between academia, official statistics and the public. As part of this endeavour, she joined forces with the Bavarian State Office for Statistics and Data Processing and the IAB, and co-founded (as representative of the University of Bamberg) the Statistical Network of Bavaria in 2013. Even more important was her involvement in the last census in Germany. When the German statistical system started preparing for the 2011 Population Census (the first census in Germany since 1987), which was to feature novel methodology combining population registers and a large household survey, the German ministry of the interior established a scientific advisory body and invited Susanne to be a member of this board. In the years that followed, Susanne discussed methodological questions within the Board and with delegates of Destatis (the German national statistical institute). At the same time, she participated in numerous discussions on radio and on television, trying to convince the audience of the merits of the upcoming census. In 2017, some German states went to the Constitutional Court, claiming that parts of the census methodology were not in line with the constitution. Susanne served as a technical expert during the hearing, and may surely take the main credit for the court's 2018 decision in favour of the census.

Susanne was a wonderful mentor for her numerous $\mathrm{PhD}$ students. She always offered support, seeking any opportunity to promote the work of her students as well as to introduce them to the scientific community. The enthusiasm, which she showed for any proposed research idea (no matter how minor), motivated her students to keep working towards their degree even in times of little progress and much frustration.

For Susanne, all of her statistical collaborators were part of her family. She and her wonderfully supportive husband Hendrik would spend hours hosting the "statistical family" at their house. Many research ideas emerged from the discussions at the outdoor dining area, where Hendrik, though not a statistician, would always be there. Her warm and embracing nature and her remarkable energy will be deeply missed by all who had the fortune to know her. 